INTERNATIONAL JOURNAL OF

MULTIDISCIPLINARY STUDIES ON MANAGEMENT, BUSINESS, AND ECONOMY

\title{
THE IMPACT OF INNOVATION IN ARCHITECTURAL HERITAGE ON DEVELOPMENT CAPABILITIES OF SMALL AND MICRO-PROJECTS
}

\author{
Rehab Abdel Fattah Naseer*
}

Interior Design and Furniture Department, Faculty of Applied Arts, 6th October University, Egypt

\begin{abstract}
Interest in small projects began in Egypt since 1916, since the establishment of the Trade and Industry Committee with the aim of advancing, stimulating and developing various industries and crafts in Egypt. Efforts continued after that with the establishment of the Industrial Development Bank in 1947, which established a specialized department for small projects and heritage crafts, and with the end of the economic reform program in Egypt. Interest in small industries increased through the establishment of the Social Fund for Development in 1991 With the aim of providing loans at low interest rates and appropriate grace periods to provide new job opportunities for young people and graduates to contribute to solving the problem of unemployment. Law No. 141 of 2004 (Small Enterprise Development Law) defined small enterprises with every company or individual establishment that practices an economic, productive, service, or commercial activity of no less than Its paid-up capital does not exceed 50 thousand pounds and does not exceed (one million) pounds, and the number of its employees does not exceed 50 workers, and micro-enterprises do not exceed 50 thousand pounds. Whereas the interior design of the architectural heritage is an integral part of the behaviours and patterns of life to face problems such as not preserving the architectural heritage, and to activate this, the mechanisms of the innovative environment for small and micro enterprises and the design thinking were identified, and packages of programs for capacity development were proposed. Innovative and creative projects for small and micro enterprises through the development and innovation of new products that adhere to international standards of quality, as it was concluded that an innovative environment must be provided for the architectural heritage to benefit from the results of research and projects to improve methods and methods of production and improve quality for small and micro heritage projects Filigree.
\end{abstract}

Keywords

ARCHITECTURAL HERITAGE- SMALL PROJECTS- MICRO PROJECTS.

\section{Introduction}

Innovation - is the process of creating or birthing something new, and the new production, whether it is an invention or an idea, must be original. Without originality and modernity, there is no creativity. Innovation is an ability that leads to renewal in science, performance, arts and ideas, and it is one of the characteristics of the specificity of interaction, communication and continuity with what the culture and skill of the artist or creator of the heritage produced. Creativity, innovation and renewal are essential elements for developing life. Some people are seated, lazy, and live on others' efforts. And some of them are workers, with varying degrees of seriousness, perseverance and perseverance, but they are traditional stereotypes, do not have the ability to improve reality and present the new, they repeat themselves, and lead to an increase in production. ... is necessary without which life cannot arise. But there is a third team, which has to do with renewal and improvement. It is the team of innovators, the team that is not satisfied with dealing with what is there, nor by repeating it and walking on familiar patterns, but has the tendency and ability to change, if it is a change for the better then it is innovation, and its owners are a rare class in life, And they must rely on transforming the tide of society for the better. Culture and local heritage represent a huge amount of visual symbols that represent the plastic language that is passed down through the generations, and the plastic artist in every era has the ability to digest such symbols and formulate them in a spirit and innovation commensurate with the era in which he lives. The innovator deals with the elements of heritage, investigating Belonging or relationship to his environment, provided that his discussion is an addition and innovation, and we will finally address the concept of small and micro enterprises and their relationship to innovation and heritage.

Research problem : heritage.

The lack of recognition of the innovative mind and its urging to innovate, especially in the architectural

\footnotetext{
* Corresponding author President-office@o6u.edu.eg
} 
Lack of interest in small and micro enterprises through rooting the concept of innovation.

Research importance:

- The importance of research is due to shedding light on the distinctive features of the innovator and the innovation process, whose knowledge leads to the development of the heritage innovation process.

-Development of innovation in small and micro enterprises.

Results

If the presence of creative people is important in every circumstance, then in conditions of weakness, stagnation and frustration, their presence is extremely important, as there is no way out of crises except with the presence of talents and distinguished competencies. This requires an in-depth analysis of these elements and units so that they are considered vocabulary or letters that are formed to give useful phrases In the form of contemporary works of art derived from heritage, when the artist designs his work, he achieves himself by expressing his feelings, achieving a goal he seeks and with the participation of others.

\section{References}

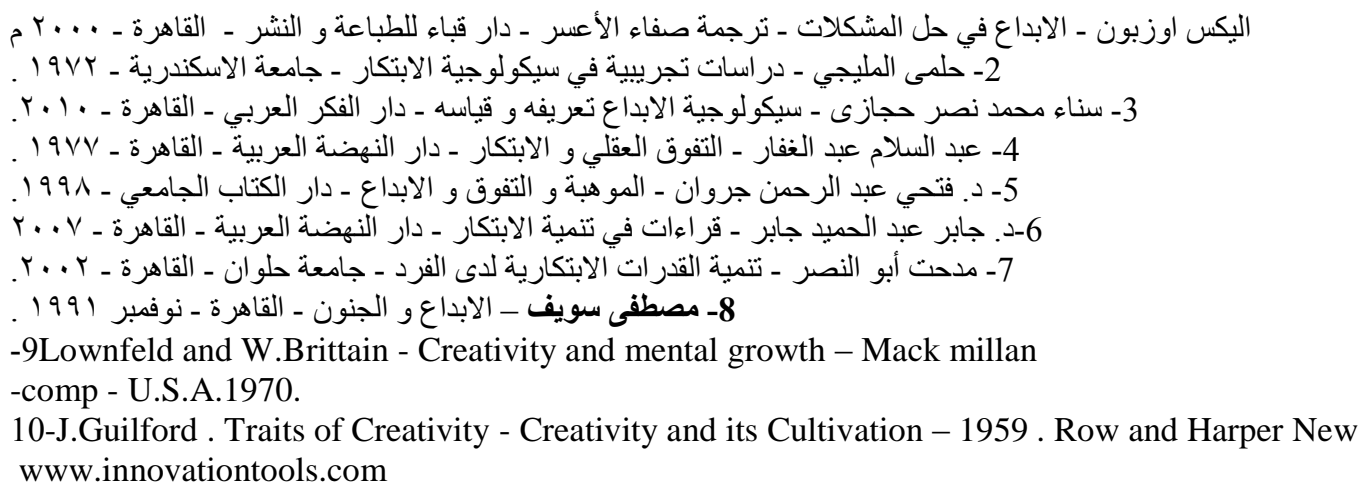

Received: February 15, 2018

Accepted: April 20, 2018 